\title{
Inflammatory bowel disease in the Bedouin Arabs of southern Israel: rarity of diagnosis and clinical features
}

\author{
H S Odes, D Fraser, P Krugliak, D Fenyves, G M Fraser, A D Sperber
}

\begin{abstract}
A prospective epidemiological and clinical study of ulcerative colitis and Crohn's disease was undertaken in the Bedouin Arabs of southern Israel between 1981 and 1990 . There were six patients with ulcerative colitis and the prevalence rate in 1990 was calculated to be $9 \cdot 8 / 10^{5}(95 \%$ confidence intervals $3 \cdot 6-17 \cdot 4)$ in the total population, or $6 \cdot 2 / 10^{5}(0.8-22 \cdot 5)$ in men and $13.7 / 10^{5}(3.7-35 \cdot 0)$ in women. Two cases of Crohn's disease occurred, both in women; the prevalence rate was $3 \cdot 2 / 10^{5}(0.4-$ $11.8)$ in the entire population, and $6.8 / 10^{5}(0.8-$ 17.5 ) in women. The prevalence rates (age adjusted) in Arabs were significantly lower $(\mathbf{p}<0.01)$ than the corresponding rates in the local Jewish populations. The Bedouin patients were aged mean (SD) $34.0(16.4)$ years at time of diagnosis. The clinical features of both diseases resembled those in the Jewish and other reported populations. It is suggested that the exposure of the Bedouin Arabs to the environmental causative factors of ulcerative colitis and Crohn's disease has hitherto been limited and thereby accounts for the rarity of these diseases in this population.
\end{abstract}

Inflammatory bowel disease occurs with variable frequency in different populations. While the prevalence rates are high in the countries of northern Europe, the United States, and other westernised lands, they are much lower in southern Europe, Asia, and Africa. ${ }^{12}$ In Israel, the prevalence rates of ulcerative colitis and Crohn's disease were lower in Jewish immigrants from Arab countries (Oriental Jews) than in immigrants from Europe and the United States..$^{3-8}$ A study from Kuwait suggested that inflammatory bowel disease is uncommon in Arabs. ${ }^{9}$ The frequency of these illnesses and their clinical features in the Bedouin Arabs of Israel have not been reported previously. We therefore undertook a prospective study of ulcerative colitis and Crohn's disease in the Bedouin Arabs of southern Israel and report here our epidemiological and clinical findings.

\section{Methods}

A prospective study was performed on the Bedouin Arabs of southern Israel between 1981 and 1990 . About $70 \%$ of the Arabs are enrolled in prepaid health plans; the remainder use either private medical facilities or are dependent on subsidised medical care. Patients with the diagnosis of ulcerative colitis and Crohn's disease were located at the Soroka University Hospital in
Beer Sheva (the only hospital in the district) and in the community clinics, utilising methods previously described in detail. ${ }^{3-6}$ General practitioners were encouraged to refer all patients with suggestive symptoms to the Inflammatory Bowel Diseases Clinic at Soroka University Hospital. The commoner bacterial, amoebic, and tuberculous infections were rigorously excluded. A detailed computerised questionnaire was completed for each patient. Data on the structure of the population were obtained from census enumerations of the Central Bureau of Statistics, Jerusalem. ${ }^{10}$

Results are shown as mean (SD). The prevalence rates are expressed per $10^{5}$ population, and the prevalence date was 30 June 1990. Confidence intervals (CI) are calculated at the $95 \%$ limit." Statistical comparison between the prevalence rates in Arabs and the rates previously documented in Jews ${ }^{5}$ was performed using age adjustment of rates to the world standard population and the odds ratio. ${ }^{12} 13$

\section{Results}

There were 61299 Bedouin Arabs living in southern Israel in 1990 . The male to female ratio was $1 \cdot 1$. In men, $56 \cdot 4 \%$ were aged $0-14$ years, $30 \cdot 4 \%$ were $15-34$ years, $10 \cdot 1 \%$ were $35-54$ years, and $3 \cdot 1 \%$ were $55+$ years. In women the respective percentages were $57 \cdot 6 \%, 28.6 \%$, $10.5 \%$, and $3.3 \%$. About $80 \%$ of the population was rural but most lived within short distances from the large towns.

Altogether eight patients with inflammatory bowel disease were diagnosed during the study period (no cases were diagnosed before 1981). There were two men and six women, ratio 0.33 . These patients were aged mean (SD) $34 \cdot 0(16 \cdot 4)$ years at a time of diagnosis, and the time interval between onset of symptoms and diagnosis was not more than one year. All the patients were alive on the prevalence date.

Six of the patients had ulcerative colitis - two men and four women (Table I). These patients presented with diarrhoea and usually rectal bleeding. Their disease was most often limited to the distal large bowel and there were no cases with total colitis. Compatible or typical histology was obtained in all patients at colonoscopic biopsy. The patients were treated with salazopyrine or 5-aminosalicylic acid and three of them also required corticosteroids. These patients have all run a relapsing course since diagnosis and have not developed serious disease or required surgery.

Crohn's disease was discovered in two women who presented with subacute obstruction of the

\author{
Correspondence to: \\ Dr H S Odes, Inflammatory \\ Bowel Diseases Unit, Soroka \\ 151, Beer-Sheva 84101, Israel. \\ Accepted for publication \\ Accepted for publicat
19 November 1990
}


TABLE I Clinical features of ulcerative colitis (UC) and Crohn's disease (CD) in the Bedouin Arabs

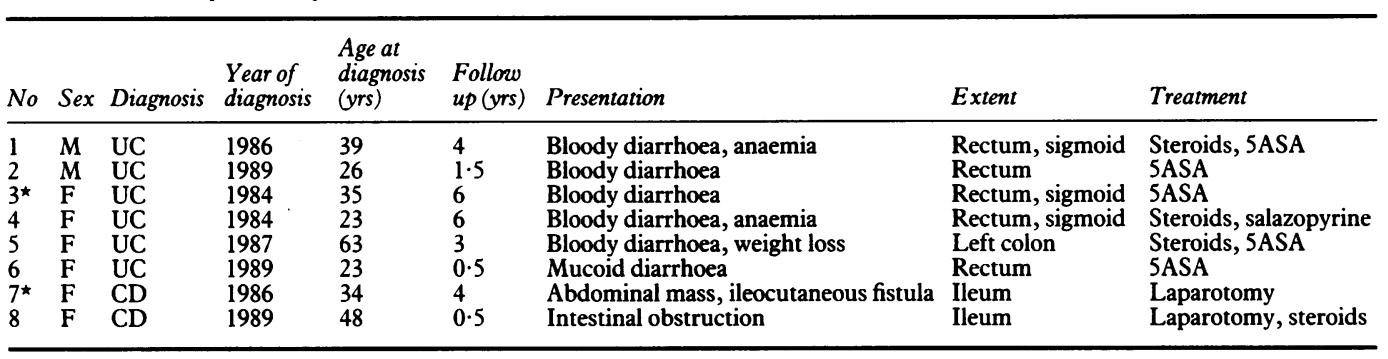

5ASA $=5$-aminosalicylic acid. ${ }^{\star}$ Urban cases (all the others were rural).

ileum (Table I). Their diagnosis was made at laparotomy, and this also ensured that tuberculosis of the bowel was excluded. The illness in these patients has run a fairly benign course since their initial presentation, with abdominal pain and diarrhoea being the only symptoms. One patient required a course of corticosteroids after exacerbation of the disease. Neither has needed a second operation. Extraintestinal complications have not occurred in either the Crohn's disease or ulcerative colitis patients and their nutritional status remains normal.

The prevalence rate of ulcerative colitis was calculated to be $9 \cdot 8 / 10^{5}(95 \%$ CI $3.6-17 \cdot 4)$ in the total Bedouin population, $6 \cdot 2 / 10^{5}(0 \cdot 8-22 \cdot 5)$ in men, and $13 \cdot 7 / 10^{5}(3 \cdot 7-35 \cdot 0)$ in women (Table II). The prevalence rate of Crohn's disease was $3 \cdot 2 / 10^{5}(0 \cdot 4-11 \cdot 8)$ in the entire population and $6 \cdot 8 / 10^{5}(0 \cdot 8-17 \cdot 5)$ in women (there were no cases in men). The age specific prevalence rates were generally low for both diseases (Table II).

Prevalence rates in the Bedouin were compared with the prevalence rates reported ${ }^{5}$ in the Jewish population in 1987 (ulcerative colitis: 89/ $10^{5}$ in the total population, $81 / 10^{5}$ in men, and $98 /$ $10^{5}$ in women; Crohn's disease: $30 / 10^{5}$ in the total population and $40 / 10^{5}$ in men and women respectively). The rates for ulcerative colitis in the whole population and Crohn's disease in women were significantly lower in the Bedouin compared with Jews (odds ratios: $0 \cdot 124$ and 0.171 respectively, with $\mathrm{p}<0.01$ for both). However, the age specific prevalence rates (age groups: $15-34,35-54$, and 55+ years) were not significantly different between Arabs and Jews, owing to the small number of Arab cases.

Regarding risk factors, the Bedouin patients showed evidence of undergoing a limited process of westernisation. Thus, the men worked in the towns, their diet was a mixture of Israeli and Bedouin food, and they smoked in moderation. The women enjoyed more of a traditional Bedouin diet and worked as housewives. All but one had produced several children and none was using oral contraceptives. No patients had a

TABLE II Age specific prevalence rates of ulcerative colitis and Crohn's disease in the Bedouin Arabs on 30 fune $1990^{\star}$. (Rates per $10^{5}$ population ( $95 \%$ confidence intervals).)

\begin{tabular}{|c|c|c|c|c|c|}
\hline \multirow{2}{*}{$\begin{array}{l}\text { Age } \\
\text { group } \\
\text { (yrs) }\end{array}$} & \multicolumn{3}{|l|}{ Ulcerative colitis } & \multicolumn{2}{|l|}{ Crohn's disease } \\
\hline & Total population & Men & Women & Total population & Women \\
\hline $\begin{array}{l}15-34 \\
35-54 \\
55+ \\
\text { All ages }\end{array}$ & $\begin{array}{c}16 \cdot 5(3 \cdot 4-43 \cdot 4) \\
31 \cdot 8(3 \cdot 8-114 \cdot 6) \\
50 \cdot 3(1 \cdot 3-279 \cdot 9) \\
9 \cdot 8(3 \cdot 6-17 \cdot 4)\end{array}$ & $\begin{array}{l}10 \cdot 3(0 \cdot 3-57 \cdot 3) \\
30 \cdot 9(0 \cdot 8-170 \cdot 3) \\
0 \\
6 \cdot 2(0 \cdot 8-22 \cdot 5)\end{array}$ & $\begin{array}{c}23 \cdot 9(2 \cdot 9-86 \cdot 3) \\
32 \cdot 7(0 \cdot 8-182 \cdot 1) \\
101 \cdot 9(2 \cdot 6-567 \cdot 8) \\
13 \cdot 7(3 \cdot 7-35 \cdot 0)\end{array}$ & $\begin{array}{c}5 \cdot 5(0 \cdot 1-30 \cdot 8) \\
15 \cdot 9(0 \cdot 4-88 \cdot 4) \\
0 \\
3 \cdot 2(0 \cdot 4-11 \cdot 8)\end{array}$ & $\begin{array}{l}12 \cdot 0(0 \cdot 3-66 \cdot 6) \\
32 \cdot 7(0 \cdot 8-182 \cdot 1) \\
0 \\
6 \cdot 8(0 \cdot 8-17 \cdot 5)\end{array}$ \\
\hline
\end{tabular}

$\star$ There were no cases of ulcerative colitis or Crohn's disease in the age group 0-14 years, and no cases of Crohn's disease in men. positive family history of inflammatory bowel diseases. All but two patients were of rural origin (Table I).

\section{Discussion}

We have detected low prevalence rates of both ulcerative colitis $\left(9 \cdot 8 / 10^{5}\right)$ and Crohn's disease $\left(3 \cdot 2 / 10^{5}\right)$ in the Bedouin Arabs. Furthermore, inflammatory bowel disease in southern Israel is significantly rarer in Arabs than Jews even though the clinical features of these diseases are similar in both populations. Since $90 \%$ of Jews have health insurance compared with $70 \%$ of Arabs, it may be speculated that this factor militates against case ascertainment in Arabs compared with Jews. Also, the diagnosis of inflammatory bowel disease can be difficult in largely rural populations such as the Bedouin. Despite these two factors, we believe that we have detected most or all affected patients with inflammatory bowel disease in the Bedouin Arabs, since the health care system encourages rapid referal to gastroenterologists whenever abdominal disease seems to be chronic or recurrent.

The only previous epidemiological study of inflammatory bowel disease in Arabs was from Kuwait, where hospital prevalence rates of ulcerative colitis and Crohn's disease were quite low.' Inflammatory bowel diseases are uncommon in non-western countries. ${ }^{121416}$ Since there can be little genetic similarity between these diverse peoples, it is hypothesised that non-western populations have not been exposed sufficiently to the postulated infective agents, or 'risk factors', related to urbanisation, oral contraception, smoking, and a westernised (low dietary fibre, high refined sugar) diet. ${ }^{16-18}$ The Bedouin Arabs have adopted western living and eating habits to a limited extent in the past 50 years, and this possibly accounts for the recent occurrence of inflammatory bowel disease in this population. This is also the accepted explanation for the rising incidence of inflammatory bowel disease in Oriental Jews since their arrival in Israel. ${ }^{3-8}$

The clinical aspects of ulcerative colitis and Crohn's disease in the Bedouin Arabs resembled those of our Jewish population and were similar to other reported populations. Ulcerative colitis is generally a milder illness than Crohn's disease in Israel ${ }^{46}$ and this was found too in the Bedouin Arabs. The preponderance of female patients in the Arabs could be the result of the small number of cases in this series. It should, however, be noted that Jewish women also outnumber men 
for both ulcerative colitis (male:female ratio $0 \cdot 8$ ) and Crohn's disease (ratio 0.5). ${ }^{5}$ The Arabs' mean age at diagnosis, 34 years, was also like that of the Jews. ${ }^{5}$

In conclusion, inflammatory bowel disease is rare in the Bedouin Arabs of Irael, as in other non-western populations. It will be interesting to see whether these diseases will become more common with the passage of time.

1 Mayberry JF. Recent epidemiology of ulcerative colitis and Crohn's disease. Int $f$ Colorectal Dis 1989; 4: 59-66.

2 Shivananda S, Hordijk ML, Pena AS, Mayberry JF, Van Blankenstein $M$, eds. Proceedings of the first European Community workshop on inflammatory bowel disease. Scand f Gastroenterol 1989; 24 (suppl 170): 1-102.

3 Krawiec J, Odes HS, Lasty Y, Krugliak P, Weitzman S. Aspects of the epidemiology of Crohn's disease in the Jewish population in Beer Sheva, Israel. Isr f Med Sci 1984; 20: 16pop.

4 Odes HS, Fraser D, Krawiec J. Incidence of idiopathic ulcerative colitis in Jewish population subgroups in the Bee Sheva region of Israel. Am $\mathcal{f}$ Gastroenterol 1987; 82: 854-8.

5 Odes HS, Fraser D, Krawiec J. Inflammatory bowel disease in migrant and native Jewish populations of southern Israel. Scand $\mathcal{F}$ Gastroenterol 1989; 24 (suppl 170): 36-8.

6 Odes HS, Fraser D, Krawiec J. Ulcerative colitis in the Jewish population of Southern Israel 1981-85: epidemiological and clinical study. Gut 1987; 28: 1630-6.
7 Grossman A, Fireman Z, Lilos P, Novis B, Rozen P, Gilat T. Epidemiology of ulcerative colitis in the Jewish population of central Israel 1970-1980. Hepatogastroenterology 1989; 36: 193-7.

8 Fireman Z, Grossman A, Lilos P, Eshchar Y, Theodor E, Gilat $T$. Epidemiology of Crohn's disease in the Jewish population of central Israel, 1970-1980. Am $\mathcal{F}$ Gastroenterol 1989; 84: $255-8$.

9 Al-Nakib B, Radhakrishnan S, Jacob GS, Al-Liddawi H, Al-Ruwaih A. Inflammatory bowel disease in Kuwait. Am Al-Ruwaih A. Inflammatory bo

10 Statistical abstract of Israel. Jerusalem: Central Bureau of Statistical abstract of Istics, 1988: vol 40.
Statistict

11 Waterhouse J, Muir C, Correa P, Powell J. Cancer incidence in five continents. Vol III. Lyons: IARC Sci Pub, 1976; 15: 228-32.

12 Haenszel W, Loveland DB, Sirkin MG. Lung cancer mortality as related to residence and smoking histories in white males. f Natl Cancer Inst 1962; 28: 947-1001.

13 Bailer JC, Ederer F. Significance factor for the ratio of a Poisson variable to its expectation. Biometrics $1964 ; 20: 639$ 43.

14 Yoshida Y, Murata Y. Inflammatory bowel disease in Japan: studies of epidemiology and pathogenesis. Med Clin North Am 1990; 74: 67-90.

15 Mayberry J, Mann R. Inflammatory bowel disease in rural sub-Saharan Africa: rarity of diagnosis in patients attending mission hospitals. Digestion 1989; 44: 172-6.

16 Whelan G. Epidemiology of inflammatory bowel disease. Med Clin North Am 1990; 74: 1-12.

17 Calkins BM, Mendeloff AI. Epidemiology of inflammatory bowel disease. Epidemiol Rev 1986; 8: 60-91.

18 Madar Z, Odes HS. Dietary fiber research: the use of dietary fiber in inflammatory bowel diseases. Prog Biochem Pharmacol 1990; 24: 101-6. 